\section{Crystal ball gazing}

\author{
Phil Wiffen
}

The PwC Health Research Institute ${ }^{1}$ aims to provide intelligence, perspective and analysis on trends affecting health related industries'. Each year they look forward to what they consider to be the main issues to be faced in the coming year. While they are focused on issues in the USA, there are trends which we would do well to take note of. These possible trends also raise questions about the way we run our pharmacy services. The trends are helpfully described in Healthcare IT News. ${ }^{2}$

The report ${ }^{3}$ looking into 2018 highlights 12 trends and six of these are worth considering.

1. 'Meet your co-worker-Artificial intelligence (AI)'

Increasingly, AI is appearing in hospital pharmacies in the form of robotics for pack dispensing but also in cytotoxic and intravenous additive preparations. PwC predicts a trend where more tasks will be automated such as routine paperwork and scheduling. However, $75 \%$ of executives said they planned to move in this direction but lacked the ability to implement the technology.

\section{2. 'Health reform isn't over'}

Very much a US focus but I suspect many of us will be faced with major reforms as our technical ability in healthcare continues to outstrip our ability to afford it.

\section{3. 'Time to tackle the opioid crisis'}

This again has a strong US focus but is a worldwide problem. PwC sees one of the solutions as a wider sharing of data to identify 'at risk' patients. There may be simpler ways than this such as being cautious about the use of opioids for chronic painful conditions especially back pain, and stopping opioids in patients who see little analgesic benefit from them.

Correspondence to Professor Phil Wiffen, Pain Research Unit, Churchill Hospital, Oxford OX3 7LE, UK; phil.wiffen@ndcn.ox.ac.uk

\section{4. 'Securing the internet of things'}

This clearly affects hospital management at the highest level but how secure are our pharmacy systems to a threat from a cybersecurity breach? How would you cope if your pharmacy system went down for days or weeks? What would be the impact on patient care?

5. '2018 is the year of strategic patient experience'

PwC argues that the patient experience has to improve but they were told that balancing patient experience with employee job satisfaction is a barrier to efforts to improve the patient experience. That is a sad indictment of healthcare services. How much of our pharmacy services are based on the needs of the staff rather than the needs of the patients we care for? Is it time to start a change?

\section{6. 'Disaster preparation'}

Disasters come in a number of forms. They may be natural such as floods or earthquakes, or given the increasing threat of terrorist action and the tragedies seen across Europe, hospitals need to be ready to cope with whatever comes. Does your hospital pharmacy disaster planning go beyond having a backup of essential items and consider the potential impact on patients, pharmacy staff and medicine supplier?

Given the challenge that these items present I looked back to the 2017 version. ${ }^{4}$ Some of these are continued into 2018 but the ones of note are:

1. 'Pharma forming partnerships with patients'

PwC suggests that Pharma may well want to provide additional services to patients such as helping patients collect, analyse and understand their own health data. To some extent, this is already happening with glucose monitoring for diabetes but there is scope for a much wider collaboration. The question is what impact might this have on health services? Will hospital pharmacies also be able to access the data?
2. 'Prepare for emerging technologies' Again AI is mentioned along with drones and virtual reality. PwC believes that the healthcare industry is lagging behind other industries in this respect and needs to catch up.

3. 'The battle against infectious diseases' A call for more development which may need to be funded by governments but also the need for international cooperation as new diseases emerge such as Zika. 4. 'Nutrition takes a more central role in health'

It is often said that in the UK we have a national illness service rather than a health service. A focus on nutrition may well lead to the prevention of costly conditions and to the improvement of the general health of a population. Pharmacists may need to take this challenge on board alongside other specialist colleagues.

5. 'Drug companies put the brakesgently-on prices'

Well I guess we end with what might be a rye smile! A year on from this gaze in the crystal ball is this the case?

I am not a believer in crystal balls but this informed look into development trends may well help us to be prepared for what is coming in our direction.

Competing interests None declared.

Provenance and peer review Commissioned; internally peer reviewed.

(C) European Association of Hospital Pharmacists (unless otherwise stated in the text of the article) 2018. All rights reserved. No commercial use is permitted unless otherwise expressly granted.

\section{Check for updates}

To cite Wiffen P. Eur J Hosp Pharm 2018;25:175.

Eur J Hosp Pharm 2018;25:175.

doi:10.1136/ejhpharm-2018-001630

\section{REFERENCES}

1 PwC's Health Research Institute (HRI). Medical cost trend: Behind the numbers 2019. https://www.pwc. com/us/en/health-industries/health-research-institute. html (accessed Jun 2018).

2 Healthcare IT News. Next-gen revenue cycle to refine value-based care with advanced analytics. http://www. healthcareitnews.com/ (accessed Jun 2018).

3 Healthcare IT News. Here are the 12 healthcare issues that will define 2018, according to PwC. http://www. healthcareitnews.com/news/here-are-12-healthcareissues-will-define-2018-according-pwc (accessed Jun 2018).

4 Healthcare IT News. PwC's top 10 healthcare industry issues for 2017. http://www.healthcareitnews.com/ news/pwcs-top-10-healthcare-industry-issues-2017 (accessed Jun 2018). 